\title{
ZnT3 mRNA levels are reduced in Alzheimer's disease post-mortem brain Nancy Beyer ${ }^{1}$, David TR Coulson ${ }^{1}$, Shirley Heggarty ${ }^{2}$, Rivka Ravid ${ }^{3}$, G Brent Irvine ${ }^{1}$, Jan Hellemans ${ }^{4}$ and Janet A Johnston*1
}

Address: ${ }^{1}$ Centre for Public Health, School of Medicine, Dentistry and Biomedical Sciences, Queen's University Belfast, Northern Ireland, ${ }^{2}$ Genomics Core Facility, Queen's University Belfast, Regional Genetics Centre, Belfast City Hospital, Northern Ireland, ${ }^{3}$ Brain Bank Consultants, Netherlands Institute for Neurosciences, Meibergdreef 47, 1105 BA Amsterdam, the Netherlands and ${ }^{4}$ Center for Medical Genetics Ghent, Ghent University Hospital, B-9000 Ghent, Belgium

Email: Nancy Beyer - nancybeyer@gmx.de; David TR Coulson - dtrcoulson@googlemail.com; Shirley Heggarty - s.heggarty@qub.ac.uk; Rivka Ravid - info@brainbankconsultants.com; G Brent Irvine - b.irvine@qub.ac.uk; Jan Hellemans - Jan.Hellemans@ugent.be; Janet A Johnston* - j.a.johnston@qub.ac.uk

* Corresponding author

Published: 23 December 2009

Molecular Neurodegeneration 2009, 4:53 doi:10.1186/1750-1326-4-53
Received: 3 September 2009

Accepted: 23 December 2009

This article is available from: http://www.molecularneurodegeneration.com/content/4/I/53

(C) 2009 Beyer et al; licensee BioMed Central Ltd.

This is an Open Access article distributed under the terms of the Creative Commons Attribution License (http://creativecommons.org/licenses/by/2.0), which permits unrestricted use, distribution, and reproduction in any medium, provided the original work is properly cited.

\begin{abstract}
Background: $\mathrm{ZnT3}$ is a membrane $\mathrm{Zn}^{2+}$ transporter that is responsible for concentrating $\mathrm{Zn}^{2+}$ into neuronal presynaptic vesicles. $\mathrm{Zn}^{2+}$ homeostasis in the brain is relevant to Alzheimer's disease $(A D)$ because $\mathrm{Zn}^{2+}$ released during neurotransmission may bind to $A \beta$ peptides, accelerating the assembly of $A \beta$ into oligomers which have been shown to impair synaptic function.

Results: We quantified ZnT3 mRNA levels in Braak-staged human post mortem (pm) brain tissue from medial temporal gyrus, superior occipital gyrus, superior parietal gyrus, superior frontal gyrus and cerebellum from individuals with $A D(n=28)$, and matched controls $(n=5)$ using quantitative real-time PCR. ZnT3 mRNA levels were significantly decreased in all four cortical regions examined in the $A D$ patients, to $45-60 \%$ of control levels. This reduction was already apparent at Braak stage 4 in most cortical regions examined. Quantification of neuronal and glial-specific markers in the same samples (neuron-specific enolase, NSE; and glial fibrillary acidic protein, GFAP) indicated that loss of cortical $\mathrm{ZnT3}$ expression was more pronounced, and occurred prior to, significant loss of NSE expression in the tissue. Significant increases in cortical GFAP expression were apparent as the disease progressed. No gene expression changes were observed in the cerebellum, which is relatively spared of $A D$ neuropathology.

Conclusions: This first study to quantify $\mathrm{ZnT3}$ mRNA levels in human pm brain tissue from individuals with $A D$ and controls has revealed a significant loss of $Z n T 3$ expression in cortical regions, suggesting that neuronal cells in particular show reduced expression of ZnT3 mRNA in the disease. This suggests that altered neuronal $\mathrm{Zn}^{2+}$ handling may be an early event in $A D$ pathogenesis.
\end{abstract}

\section{Background}

$\mathrm{ZnT3}$ is a $\mathrm{Zn}^{2+}$ transporter which is a member of the solute carrier family 30 (SLC30), previously known as the cation diffusion facilitator (CDF) family. Studies in mice have shown that ZnT3 (SLC30A3) is primarily expressed in the brain, particularly in the hippocampus, amygdala and cer- 
ebral cortex [1]. Within neurons, ZnT3 protein was detected at membranes of small, round, clear synaptic vesicles from mossy fibre boutons in mouse and monkey hippocampus [1,2]. ZnT3 is responsible for concentrating $\mathrm{Zn}^{2+}$ into these vesicles [3], which is co-released with glutamate upon depolarization $[4,5]$. Synaptic free $\mathrm{Zn}^{2+}$ levels can reach high concentrations during neurotransmission (hundreds of $\mu \mathrm{M}$ ) and its exact role at the synapse is unclear, although it has been shown to modulate postsynaptic events (both excitatory and inhibitory), probably via effects on $\mathrm{GABA}_{\mathrm{A}}[6]$ and NMDA receptors [7-9].

Several findings indicate that $\mathrm{Zn}^{2+}$ homeostasis in the brain is of relevance in Alzheimer's disease (AD). A $\beta$ peptides are found aggregated in amyloid plaques, one of the characteristic hallmarks of AD neuropathology. A $\beta$ binds $\mathrm{Zn}^{2+}$ and this rapid interaction accelerates $\mathrm{A} \beta$ aggregation on solid templates [10]. Current evidence indicates that lower order, soluble, A $\beta$ assemblies (known as oligomers) are important in $\mathrm{AD}$ pathophysiology and that they impair synaptic function [11]. $\mathrm{Zn}^{2+}$ released during neurotransmission was recently shown to play a key role in mediating formation of these $A \beta$ oligomers at synapses [12]. $\mathrm{Zn}^{2+}$-induced $A \beta$ aggregation can be prevented, and even reversed, with chelating agents [13]. Treatment of a transgenic mouse model relevant to AD (Tg2576) for three months with the metal chelating agent DP-109 reduced the appearance of amyloid plaques and increased soluble A $\beta$ levels [14]. Crossing these animals with ZnT3 knock-out mice also resulted in reduced plaque load and the animals displayed markedly less cerebral amyloid angiopathy $[15,16]$. In patients with $\mathrm{AD}, \mathrm{Zn}^{2+}$ levels have been reported to be elevated in serum $[17,18]$, and in brain tissue [19-21], particularly associated with amyloid plaques, cerebral amyloid angiopathy, and in cell bodies and dendrites of neurofibrillary tangle-positive neurons [22-24]. Compounds acting as metal ion chelators, such as clioquinol and PBT2, have entered clinical trials for AD. A slight improvement in clinical ratings was observed in twenty AD patients after a three week treatment with clioquinol [25], and it reduced plasma $A \beta_{42}$ levels and increased $\mathrm{Zn}^{2+}$ levels in a phase two clinical trial in $\mathrm{AD}$ [26].

These findings have prompted investigation of ZnT3 protein expression in the brains of another AD transgenic mouse model (APPswe/PS1dE9) and in AD patients. ZnT3 protein was abundantly detected in amyloid plaques throughout the cortex and hippocampus as well as amyloid angiopathic vessels in the APPswe/PS1dE9 mice, where levels were increased in comparison to wildtype littermates [27]. ZnT3 also co-localized with amyloid plaques throughout the cerebral cortex in five AD patients and was detected in vessels with amyloid angiopathy [28], although this study did not compare expression in control human brain tissue.

The present study is the first to investigate ZnT3 mRNA expression levels in human post mortem brains from individuals with $A D$, and matched controls. We used quantitative real-time PCR (RT qPCR), a fast, straightforward and reproducible technique which is increasingly becoming the method of choice for profiling mRNA levels due to its accuracy, wide dynamic range and sensitivity [29,30]. The accuracy of this technique is however totally dependent on the use of valid reference genes for data normalisation. Traditionally, 'housekeeping genes' such as glyceraldehyde 3-phosphate dehydrogenase (GAPDH) or $\beta$-actin have been used for normalisation, but if expression of these genes is altered by the disease process, then false negative or positive results may be obtained. It is therefore essential that the expression stability of the reference gene(s) is examined and confirmed in the appropriate disease state and tissue prior to using the gene for data normalisation. To identify a stable set of reference genes, we examined the expression stability of a range of candidate reference genes in post mortem brain samples from individuals with AD, Parkinson's disease, dementia with Lewy bodies, and controls [31]. The present study used this validated set of reference genes to investigate whether ZnT3 mRNA expression was altered in Braakstaged post mortem brain tissue from individuals with AD. Braak staging enabled the AD samples to be subgrouped according to progression of the neurofibrillary tangle pathology [32]. We have also investigated the expression of a glial marker (glial fibrillary acidic protein, GFAP) and a neuronal marker (neuron-specific enolase, NSE) to investigate whether any observed variations in gene expression related to changing cell populations in the tissues sampled. We analysed five brain regions, affected to differing extents by AD neuropathology: cerebellum; medial temporal gyrus; superior occipital gyrus; superior parietal gyrus; and superior frontal gyrus.

This study identified significant reductions in cortical ZnT3 mRNA levels in AD, which occurred prior to overt loss of NSE expression, indicating that impaired neuronal $\mathrm{Zn}^{2+}$ handling may be an early event in AD pathogenesis.

\section{Methods}

\section{Post-mortem brain tissue samples}

Human post mortem brain tissue was obtained from The Netherlands Brain Bank (Netherlands Institute for Neuroscience, Amsterdam, Netherlands), in accordance with local ethical approval, whereby autopsies on donors are performed only when a written consent from the donor or next of kin exists. The tissue originated from clinically well documented and neuropathologically confirmed cases and controls, with comprehensive information on ante- 
and post-mortem (pm) factors. All tissue was Braak staged [32]. Full details about the study subjects are presented in Table 1. 28 AD patients were included ( 9 at Braak stage 4; 11 at Braak stage 5; 8 at Braak stage 6) and 5 matched controls (4 at Braak stage $1 ; 1$ at Braak stage 2). All individuals in the AD group had a clinical diagnosis of dementia or probable $\mathrm{AD}$ prior to death, and the neuropathological diagnosis was either $\mathrm{AD}$, or $\mathrm{AD} /$ Lewy body variant $(\mathrm{AD} /$ LBV), as indicated on Table 1. The latter diagnosis was applied to brains where some cortical LB were observed, in addition to classical AD pathology. All controls also underwent a full neuropathological evaluation to confirm that they were not affected by AD or any other neurode- generative disease. The tissue in this study was fresh-frozen after a generally short post-mortem delay and all tissue handling was done on dry ice to avoid thawing, which would lead to increased RNA degradation [33]. As shown in Table 1, there were no significant differences between the study groups in terms of post-mortem delay, previously reported to have a limited negative effect on brain mRNA levels [34]; or CSF $\mathrm{pH}$, shown to have a major influence on brain mRNA levels [35,36]. Mean brain weight was significantly lower in the AD group, reflecting the brain atrophy caused by the disease. Frozen tissue blocks were obtained from cerebellum and four cortical gyri (medial temporal, superior occipital, superior

Table I: Information about the study subjects

\begin{tabular}{|c|c|c|c|c|c|c|}
\hline Diagnosis & Gender & Age & Braak stage & pm delay (min) & CSF pH & Brain weight (g) \\
\hline control & $\mathrm{F}$ & 69 & I & 375 & 6.59 & 1264 \\
\hline control & $\mathrm{F}$ & 72 & I & 405 & 6.52 & 1296 \\
\hline control & $M$ & 79 & 1 & 320 & 6.72 & 1322 \\
\hline control & $M$ & 83 & 1 & 275 & 6.49 & 1422 \\
\hline control & $\mathrm{F}$ & 88 & 2 & 340 & n.d. & 1152 \\
\hline Control mean & $3 F / 2 M$ & 78.2 & 1.2 & 343 & 6.58 & $|29|$ \\
\hline$A D$ & $\mathrm{~F}$ & 84 & 4 & 230 & 6.64 & 1196 \\
\hline$A D$ & $\mathrm{~F}$ & 85 & 4 & 220 & 6.59 & 1065 \\
\hline$A D$ & $\mathrm{~F}$ & 93 & 4 & 335 & 6.65 & 1194 \\
\hline$A D$ & $\mathrm{~F}$ & 84 & 4 & 230 & 6.64 & 1196 \\
\hline$A D$ & $\mathrm{~F}$ & 87 & 4 & 240 & 6.91 & 955 \\
\hline$A D$ & $\mathrm{~F}$ & 101 & 4 & 265 & 6.93 & 1016 \\
\hline$A D$ & $M$ & 91 & 4 & 250 & n.d. & 1160 \\
\hline AD/LBV & $\mathrm{F}$ & 81 & 4 & 193 & 6.54 & 1096 \\
\hline AD/LBV & $F$ & 76 & 4 & 295 & 6.78 & 1180 \\
\hline$A D$ & $M$ & 67 & 5 & 260 & 6.62 & 1094 \\
\hline$A D$ & $\mathrm{~F}$ & 77 & 5 & 252 & 6.43 & 1151 \\
\hline$A D$ & $\mathrm{~F}$ & 77 & 5 & 215 & 6.67 & 1235 \\
\hline$A D$ & $M$ & 86 & 5 & 335 & 6.39 & 1315 \\
\hline$A D$ & $M$ & 95 & 5 & 185 & 6.4 & 1203 \\
\hline$A D$ & $M$ & 70 & 5 & 525 & 6.25 & 1220 \\
\hline AD/LBV & $M$ & 80 & 5 & 1670 & 6.19 & 1170 \\
\hline AD/LBV & $\mathrm{F}$ & 69 & 5 & 295 & 6.59 & 1039 \\
\hline AD/LBV & $\mathrm{F}$ & 84 & 5 & 365 & 6.1 & 1116 \\
\hline AD/LBV & $\mathrm{F}$ & 87 & 5 & 260 & 6.17 & 1022 \\
\hline AD/LBV & $M$ & 84 & 5 & 275 & 6.54 & 1373 \\
\hline$A D$ & $M$ & 58 & 6 & 385 & 6.42 & 1273 \\
\hline$A D$ & $\mathrm{~F}$ & 87 & 6 & 300 & 6.66 & 852 \\
\hline$A D$ & $\mathrm{~F}$ & 87 & 6 & 250 & 6.9 & 1047 \\
\hline$A D$ & $\mathrm{~F}$ & 77 & 6 & 285 & 6.74 & 1116 \\
\hline$A D$ & $\mathrm{~F}$ & 91 & 6 & 275 & 6.55 & 949 \\
\hline$A D$ & $\mathrm{~F}$ & 66 & 6 & 215 & 6.42 & 1105 \\
\hline AD/LBV & $M$ & 54 & 6 & 610 & 6.51 & 1334 \\
\hline AD/LBV & $\mathrm{F}$ & 69 & 6 & 295 & 6.41 & 1003 \\
\hline AD mean & $19 \mathrm{~F} / 9 \mathrm{M}$ & 80.3 & 5 & 340 & 6.54 & || $3 \mid$ \\
\hline
\end{tabular}

There were no statistically significant differences in age, cerebrospinal fluid (CSF) $\mathrm{pH}$ or pm delay between AD patients (Braak stages 4, 5 and 6) and controls (Braak stage I and 2). Brain weight was significantly lower in the AD patients, compared to controls ( $P=0.01$, unpaired t-test). 
parietal and superior frontal) of each individual and stored at $-80^{\circ} \mathrm{C}$.

\section{Extraction of total RNA and CDNA synthesis}

Tissue samples of approximately $100 \mathrm{mg}$ were cut from fresh-frozen post-mortem brain tissue blocks on dry ice, and incubated with QIAzol lysis reagent (Qiagen). Samples were homogenised using a TissueLyser (Qiagen) and total RNA was extracted using the RNeasy ${ }^{\circledast}$ lipid tissue mini kit (Qiagen). To study RNA integrity, total RNA preparations from cerebellum and medial temporal gyrus of six AD patients and five controls were analysed using an Agilent 2100 Bioanalyzer (Agilent Technologies) in a previous study in our laboratory (described in full by [31]). 2 $\mu \mathrm{l}$ of total RNA from each sample were used for spectrophotometric quantitation using NanoDrop ${ }^{\circledR}$ ND-1000 (NanoDrop ${ }^{\varpi}$ ). $2 \mu \mathrm{g}$ RNA were reverse transcribed using the Omniscript ${ }^{\boxplus}$ reverse transcription kit (Qiagen) according to the manufacturer's protocol, in $20 \mu \mathrm{l}$ reactions containing $0.5 \mu \mathrm{M}$ oligo-dT and $5 \mu \mathrm{M}$ random nonomer primers (Operon).

\section{Real-time PCR}

qPCR reactions were carried out with cDNA-specific Taq$\mathrm{Man}^{\circledR}$ gene expression assays using an ABI $7900 \mathrm{HT}$ realtime PCR system (Applied Biosystems). Further information about the gene expression assays is presented in Table 2 . Each reaction contained $2 \mu \mathrm{l} \mathrm{cDNA}$ (corresponding to 20 ng reverse transcribed RNA), $0.25 \mu$ l TaqMan ${ }^{\circledast}$ gene expression assay for the relevant gene, $2.5 \mu \mathrm{l} \mathrm{TaqMan}{ }^{\infty}$ universal PCR master mix (Applied Biosystems) and $0.25 \mu \mathrm{l}$ RNAse free water in a total volume of $5 \mu \mathrm{l}$. Sealed 384 well plates were subjected to the following thermal cycling conditions: $95^{\circ} \mathrm{C}$ for $10 \mathrm{~min}$, followed by 40 cycles of $95^{\circ} \mathrm{C}$ for $15 \mathrm{sec}$ and $60^{\circ} \mathrm{C}$ for $1 \mathrm{~min}$. The reactions were performed in triplicate and each QPCR run contained a non-template (negative) control and two inter-run calibrators.

\section{PCR Efficiency}

A pool of cDNAs prepared from four different brain regions of seven $\mathrm{AD}$ patients and two controls was used to generate PCR efficiency curves. 10-fold serial dilutions of the cDNA pool, ranging from $\times 1$ dilution to $\times 1000000$, were used in quadruplicate qPCR reactions, carried out as described above. Mean cycle threshold $(\mathrm{Ct})$ values for each cDNA dilution were plotted against the $\log _{10}$ of the
cDNA input, generating an efficiency plot (Figure 1). Reaction efficiency (E) for each assay was calculated using the slope of this line in the following equation: $\mathrm{E}=10^{(-1 /)}$ slope) -1 .

\section{Data Analysis}

Raw $\mathrm{Ct}$ values generated by the TaqMan ${ }^{\circledast}$ gene expression assays were imported into the qBase Plus (Biogazelle) software [15]. The qBase Plus algorithm enables normalisation to more than one reference gene and is able to take into account gene-specific $\mathrm{E}$, which distinguishes it from the ${ }^{\Delta \Delta} \mathrm{Ct}$ method [37]. In addition, it also employs the signals from the inter-run calibrators to minimize run-to-run variation [38]. In this study, ubiquitin C (UBC), succinate dehydrogenase complex-subunit A (SDHA) and beta-2microglobulin (B2M) were analysed as potential reference genes, as their expression levels were demonstrated to be sufficiently stable in human pm brain tissue affected by neurodegenerative disease in our previous study [31]. During the data normalisation process in qBase Plus it was clear that reference gene stability decreased considerably when B2M was included. We therefore used UBC and SDHA to normalise the ZnT3 data presented.

\section{Statistics}

Statistical analysis was performed using GraphPad Prism version 4.00 or InStat version 3.05 for Windows; GraphPad Software, San Diego California USA, http:// www.graphpad.com. Non-parametric statistical tests were used where data were not normally distributed, or where there were significant differences between group standard deviations.

\section{Results \\ PCR efficiency}

A pool of cDNA from four brain regions of AD patients and controls was generated and 10-fold serial dilutions assayed in order to determine PCR reaction efficiency from the slope of the $\log _{10}$ cDNA vs Ct plot. PCR reaction efficiency for the ZnT3 gene expression assay was 85\% (Figure 1). ZnT3 gene expression was normalised using the two reference genes UBC and SDHA, whose efficiencies were previously determined to be $99 \%$ and $95 \%$, respectively, in a separate study using the same cDNA pool in our laboratory [31]. The efficiency plots for all three TaqMan ${ }^{\circledast}$ gene expression assays had $\mathrm{r}^{2}$ values of $\geq$ 0.996.

Table 2: $\operatorname{TaqMan}^{\circledR}$ assay identification (ID) numbers, amplicon length and probe binding sequence

\begin{tabular}{lllc}
\hline Gene name & Assay ID & Probe Binding Sequence (5'-3') & Amplicon length \\
\hline ZnT3 & Hs00185728_ml & CAC CTG GCC ATC GAC TCC ACC GCT G & 93 \\
SDHA & Hs00417200_ml & CGC CGC CGT GGT CGA GCT AGA AAA T & 124 \\
UBC & Hs00824723_ml & GTG ATC GTC ACT TGA CAA TGC AGA T & 71 \\
B2 M & Hs99999907_ml & TTA AGT GGG ATC GAG ACA TGT AAG C & 75 \\
\hline
\end{tabular}




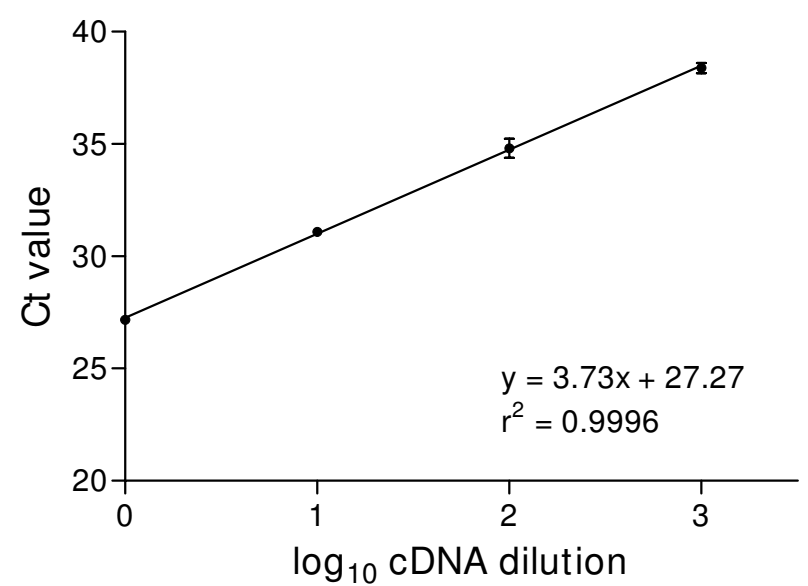

Figure I

ZnT3 efficiency plot. Quadruplicate ZnT3 qPCR analyses were carried out using the indicated dilutions of a cDNA pool, derived as described in the Methods section. Mean Ct values $\pm S D$ are presented for each dilution where the assay signal rose above the detection threshold. PCR reaction efficiency for the ZnT3 TaqMan assay (85\%) was calculated from the slope of the line as described in the Methods section.

\section{ZnT3 expression in pm brain tissue}

We analysed the gene expression level of ZnT3 in $28 \mathrm{AD}$ patients and 5 age-matched controls (Table 1). Comparison of all AD patients (Braak 4, 5 and 6) with all controls (Braak 1 and 2) showed that ZnT3 expression was significantly decreased in all four cortical regions examined in the AD patients, compared to controls. ZnT3 mRNA levels were reduced by $60 \%$ in the medial temporal gyrus ( $\mathrm{p}=$ 0.0002 , unpaired t-test); $52 \%$ in superior occipital gyrus ( $\mathrm{p}<0.0001$, unpaired t-test); $48 \%$ in superior frontal gyrus ( $\mathrm{p}=0.002$, unpaired t-test) and by $45 \%$ in the superior parietal gyrus ( $p=0.009$, Mann-Whitney). In the cerebellum, ZnT3 expression level was extremely low (less than $1 \%$ of the cortical expression levels in control samples) and no significant differences were detectable between the study groups $(20 \%$ lower in AD group, $\mathrm{p}=$ 0.55 , unpaired t-test). Figure 2 presents these data in more detail, sub-grouped according to Braak stage. The statistically significant reductions in ZnT3 expression level were already present by Braak stage 4 in all cortical regions examined, except for the superior parietal gyrus where the reduction did not reach significance until Braak stage 5 (one-way ANOVA and Tukey-Kramer multiple comparisons test).

\section{Expression of neuronal and glial-specific genes in pm brain tissue}

We determined the mRNA expression levels of NSE, as a neuronal-specific marker, and GFAP, as a glial-specific marker, in these pm brain tissue samples in a separate study (unpublished data). This identified significant changes in expression of these genes as the disease progressed (as indicated by Braak stage). NSE expression was negatively correlated with Braak stage (Spearman correlation, $\mathrm{p}<0.05$ ) in medial temporal gyrus and superior parietal gyrus, indicating significant loss of neuronal gene expression in these regions as the disease progressed. This correlation just failed to reach statistical significance in the superior frontal gyrus (Spearman correlation, $\mathrm{p}=$ 0.056). Pooling of all AD patients (Braak 4, 5 and 6), for comparison with all controls (Braak 1 and 2), showed that NSE expression was significantly decreased in superior frontal gyrus in $\mathrm{AD}$ (44\% reduction), while the decreases in NSE mRNA levels in superior parietal gyrus $(27 \%$ reduction), superior occipital gyrus (17\% reduction) and medial temporal gyrus ( $9 \%$ reduction) did not reach statistical significance. Kruskall-Wallis comparison of NSE mRNA levels in the individual Braak goups 4, 5, or 6 versus controls (Braak 1 and 2), did not reveal any statistically significant changes.

In contrast, GFAP expression showed significant positive correlations with Braak stage in medial temporal gyrus, superior occipital gyrus, superior parietal gyrus and superior frontal gyrus (Spearman correlation, $\mathrm{p}<0.05$ ), indicating significant gliosis as the disease progressed. Pooling of all AD patients (Braak 4, 5 and 6), for comparison with all controls (Braak 1 and 2), showed that GFAP expression was significantly increased in medial temporal gyrus affected by AD (to 364\% of control, $\mathrm{p}=0.01$ Mann-Whitney); in superior occipital gyrus (391\% of control, $\mathrm{p}=$ 0.01 Mann-Whitney); and superior frontal gyrus (330\% of control, $\mathrm{p}=0.04$ Mann-Whitney); but this increase just failed to achieve statistical significance in superior parietal gyrus (173\% of control, p = 0.09 Mann-Whitney). Kruskall-Wallis comparison of GFAP mRNA levels in the individual Braak goups 4, 5, or 6 versus controls (Braak 1 and 2), showed statistically significant increases at Braak stage 6 in medial temporal gyrus, superior occipital gyrus and superior parietal gyrus.

Notably, no statistically significant changes in NSE or GFAP expression were present in the cerebellum, a region which is relatively spared of AD-related neuropathology.

\section{Ratio of ZnT3 expression to neuronal and glial-specific gene expression}

The methodology employed in this study did not allow visualisation of the cellular source of the ZnT3 mRNA detected. As a first step towards exploring whether the changes we observed in ZnT3 mRNA expression were linked to the changing cell populations in the AD cortical tissue, we calculated the ratio of ZnT3 expression (CNRQ) to NSE, and to GFAP CNRQs for each individual and brain region. We reasoned that if ZnT3 expression was purely neuronal, then the ZnT3/NSE ratio in each individ- 


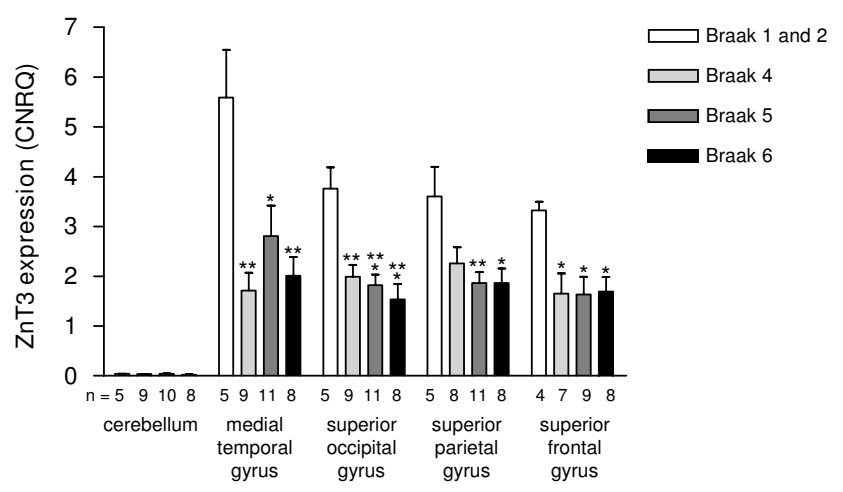

Figure 2

ZnT3 expression in AD and control brain tissue. RNA was isolated from the pm brain tissue regions indicated and reverse transcribed prior to $\mathrm{qPCR}$ analysis in triplicate, and data analysis using qBase Plus, as described in the Methods section. Columns represent the mean $\mathrm{ZnT} 3$ expression level (expressed as CNRQ) \pm SEM for each Braak stage, and the numbers at the base of each column ( $n$ ) indicate the number of individuals included in that analysis. Statistical analysis (one-way ANOVA and Tukey-Kramer multiple comparisons test) revealed significant differences between control $\mathrm{ZnT3}$ expression levels (Braak stages I and 2), and ZnT3 expression levels in the AD brain tissue (Braak stages 4, 5, and 6): * $\mathrm{p}<0.05$; ** $\mathrm{p}<0.01$; *** $\mathrm{p}<0.00$ l compared to control $\mathrm{ZnT3}$ expression in the same brain region.

ual sample would be predicted to remain constant over the course of the disease (as indicated by Braak stage).

In Figure $3(a, b, c, d, e)$, it can be seen that there was a decrease in the ZnT3 CNRQ/NSE CNRQ ratio in the superior occipital gyrus as the disease progressed which achieved borderline statistical significance, but no significant correlations between this ratio and Braak stage in any of the other brain regions investigated. There was however a consistent negative correlation between the ZnT3 CNRQ/GFAP CNRQ and Braak stage which was statistically significant in the medial temporal gyrus, superior parietal gyrus and superior occipital gyrus, and was close to statistical significance in the superior frontal gyrus (Figure $3 f, g, h, i, j$ ). These findings appear to confirm that ZnT3 expression was predominantly neuronal, since the ratio between ZnT3 and NSE expression remained relatively constant, despite the significant losses in NSE expression observed as the disease progressed in cortical regions. In addition, the increased levels of GFAP were not accompanied by increased levels of ZnT3 (negative correlation), indicating that ZnT3 may not be expressed by glial cells.

In the cerebellum, neither ratio showed any significant correlation with Braak stage.

\section{Discussion}

This study identified a significant loss of ZnT3 mRNA expression in four cortical regions in $\mathrm{AD}$ which occurred early in the course of the disease (Figure 2 ). The reductions in cortical ZnT3 gene expression, by $45-60 \%$, were already well-established at Braak stage 4 , when neocortical regions are still relatively unaffected by AD-related neurofibrillary tangle pathology and overt neuronal loss [32]. To study this directly in our samples, we analysed expression of a neuronal marker (NSE) in this Braakstaged tissue, which revealed significantly reduced NSE expression as the disease progressed, reflecting the loss of neuronal cells found in the disease. At Braak stage 4, however, we detected no significant changes in NSE expression in any cortical region. This indicates that the changes in ZnT3 expression occurred before significant neuronal losses had occurred. We provide indirect evidence that $\mathrm{pm}$ brain ZnT3 expression was predominantly neuronal (Figure 3), although our methodological approach did not allow direct identification of the cellular source of ZnT3 mRNA. The fact that the ZnT3/NSE ratio did not generally correlate with Braak stage indicates that expression of these two mRNAs was decreasing roughly in parallel, even though the ZnT3 changes were apparent earlier than NSE changes as discussed above. In addition, we identified increased GFAP expression in the AD pm brain tissue (cortical regions), reflecting the astrogliosis and astrocyte activation associated with the disease, as reported by others $[39,40]$. However, the ZnT3/GFAP ratio showed a negative correlation with Braak stage, indicating that the gliosis at later stages of the disease was not associated with increased ZnT3 expression. This suggests that glia were not a major source of the ZnT3 mRNA detected here. This is consistent with what is already known about the localization of ZnT3 protein, in neuronal presynaptic vesicle membranes $[1,2]$. The very low expression level we detected in the cerebellum was also consistent with previous reports in mice $[1,3]$. Taken together, the present study suggests that cortical neuronal cells show reduced expression of ZnT3 mRNA in brain tissue affected by AD, before NSE expression is compromised. This suggests that the loss of ZnT3 expression is not solely due to the ongoing neuronal cell death in $\mathrm{AD}$, although this undoubtedly contributes to it at later stages. One potential explanation for this finding is that whilst NSE is expressed in most neurons, Znt3 expression is more localised, as has been shown in mouse and monkey [2]. Hence, the loss of ZnT3 expression prior to loss of NSE could reflect differences in susceptibility of ZnT3-expressing neurons to AD.

This is the first direct study of ZnT3 mRNA expression in human pm brain affected by AD to our knowledge. There has been one previous study of ZnT3 protein levels in pm brain in $\mathrm{AD}$, which detected ZnT3 in the vicinity of amyloid plaques and blood vessels with amyloid angiopathy 
ZnT3/NSE ratio

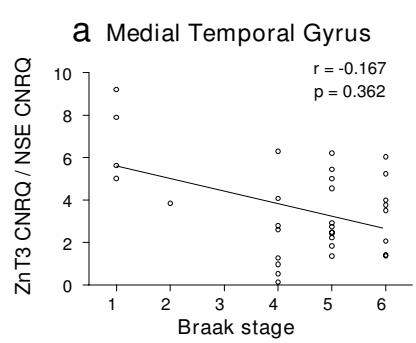

b Superior Parietal Gyrus

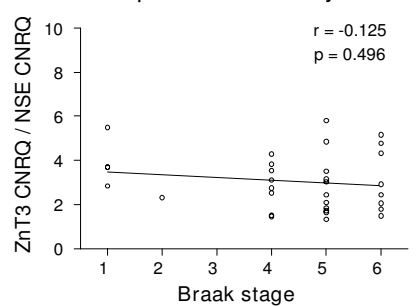

C Superior Frontal Gyrus

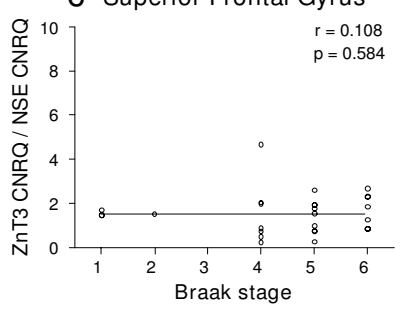

d Superior Occipital Gyrus

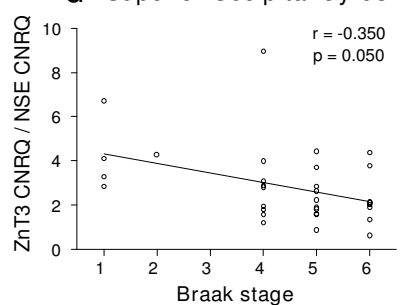

e Cerebellum

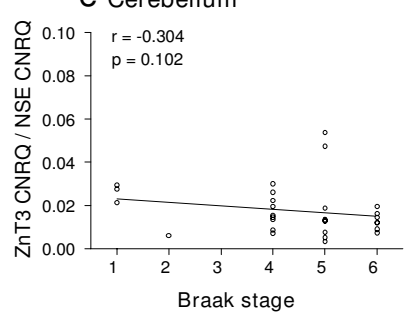

ZnT3/GFAP ratio

f Medial Temporal Gyrus

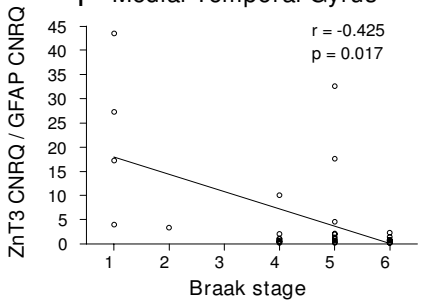

Superior Parietal Gyrus

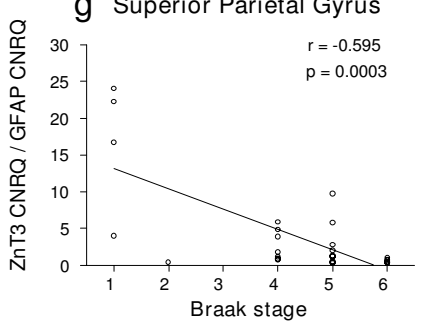

h Superior Frontal Gyrus

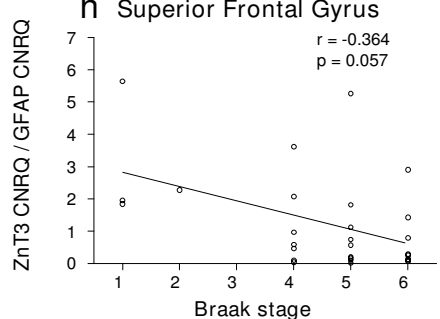

i Superior Occipital Gyrus
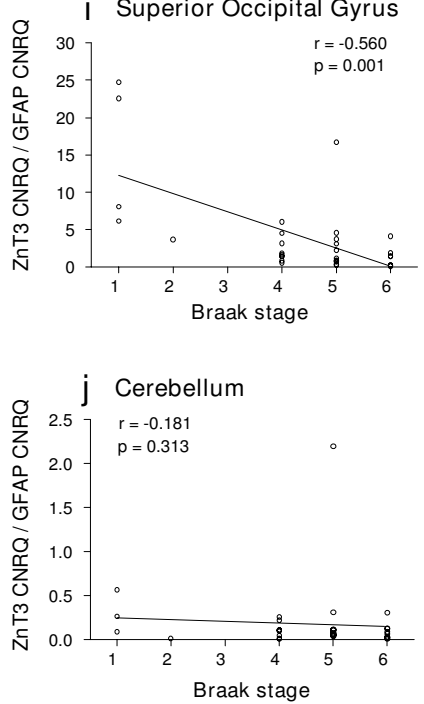

Figure 3

ZnT3/NSE and ZnT3/GFAP CNRQ in AD and control brain tissue. ZnT3 mean CNRQ values were divided by either mean NSE CNRQ, or mean GFAP CNRQ, for the same sample. This produced the ratios, which are shown plotted against the relevant Braak stage for that sample. Spearman correlation coefficients $(r)$ are displayed on each graph, alongside the relevant $P$ value. 
[28], although no control subjects were studied. Increased protein levels of other zinc transporters in the same family, which move zinc across different membranes to ZnT3 (ZnT-1, ZnT-4 and ZnT-6), have been previously reported in $\mathrm{AD}$ and mild cognitive impairment [41]. Our finding of decreased ZnT3 mRNA expression in the disease is perhaps unexpected, and would not have been predicted by previous studies of ZnT3 expression in rodents. These studies would tend to predict that increased ZnT3 mRNA expression may be associated with $\mathrm{AD}$, while decreased expression may be protective. For example, ZnT3 gene knock-out in an AD transgenic mouse model (Tg2576) resulted in reduced plaque load and cerebral amyloid angiopathy $[15,16]$, and a study of another AD transgenic mouse model (APPswe/PS1dE9) detected increased ZnT3 protein levels in comparison to wild-type littermates [27]. Previous work investigating regulation of ZnT3 expression has demonstrated a role for estrogen. Ovariectomy raised ZnT3 levels and hippocampal synaptic vesicle $\mathrm{Zn}^{2+}$ levels, while estrogen replacement lowered these [42]. These changes were attributed to estrogen-induced reductions in expression of the delta subunit of trans-Golgi network adaptor-like complex AP-3. Genetic ablation of the delta subunit of AP-3 in mocha mice leads to reduced cortical vesicular $\mathrm{ZnT3}$ protein expression and $\mathrm{Zn}^{2+}$ levels [43]. Given that early menopause and low estrogen levels have been linked to increased risk for $A D$, these findings suggest that increased ZnT3 levels may be associated with AD. However this area is not clear-cut and while human epidemiological data suggest that hormone replacement therapy (HRT) reduces $\mathrm{AD}$ risk, some experimental evidence demonstrates that HRT can increase the incidence of dementia [44]. Dietary omega-3 polyunsaturated fatty acid has also been shown to regulate ZnT3 expression. Rats supplied with an omega-3-deficient diet perinatally had increased expression of ZnT3 and increased levels of hippocampal $\mathrm{Zn}^{2+}$ in adulthood [45]. Taken together with the reported decrease in this class of fatty acids in pm brains from $\mathrm{AD}$ patients, this again predicts that increased ZnT3 expression may be associated with AD [46]. However, one study of a mouse model of accelerated aging (senescence-accelerated mouse prone 10, SAMP10) identified reduced $\mathrm{ZnT3}$ expression as the mice aged. This was associated with increased expression of GFAP and excessive hippocampal glutamatergic excitotoxicity, with deterioration of learning and memory in the mice [47]. This corresponds more closely to the changes we observed in the $\mathrm{AD}$ pm brain tissue, where ZnT3 expression was decreased, and GFAP increased.

\section{Conclusions}

The present study indicates that ZnT3 mRNA levels are significantly reduced in the cortex in $\mathrm{AD}$. The finding that this change occurs prior to overt loss of NSE expression indicates that it may precede wide-spread neuronal cell loss. The mechanism(s) underlying this change require further investigation to determine whether loss of ZnT3 expression exacerbates the disease, or occurs as a protective mechanism to reduce synaptic $\mathrm{Zn}^{2+}$ levels in the face of $\mathrm{AD}$-related increases in brain $\mathrm{Zn}^{2+}$ levels. Either way, this finding indicates that altered neuronal $\mathrm{Zn}^{2+}$ handling may be an early event in $\mathrm{AD}$ pathogenesis.

\section{Competing interests}

The authors declare that they have no competing interests.

\section{Authors' contributions}

NB designed and carried out the GPCR experiments, analysed data and drafted the manuscript. DTRC prepared RNA and the majority of the cDNA stocks and carried out NSE and GFAP qPCR analyses. SH contributed to the design and execution of the qPCR analyses. RR provided the pm brain tissue and commented on neuropathological aspects of the manuscript. GBI participated in the design and coordination of the study. JH contributed to data analysis. JAJ coordinated the study, finalised data analyses and contributed substantially to writing the manuscript. All authors read and approved the final manuscript.

\section{Acknowledgements}

We are indebted to the Alzheimer's Research Trust for funding this project via a studentship award to NB, and to the Health and Personal Social Services, N. Ireland, R\&D Office for their research funding (DTRC, GBI, JAJ). Neither of these funders contributed to study design; to data collection, analysis, or interpretation; to writing of the manuscript; or in the decision to submit the manuscript for publication. We have also benefited from participation in the Northern Ireland Centre in the Alzheimer's Research Trust's research network. Brain Bank Consultants can be found at http:// www.BrainBankconsultants.com. We thank Dr. J.G. Quinn, Dr. S. Brockbank and S. Murphy for their contributions to this study.

\section{References}

I. Palmiter RD, Cole TB, Quaife CJ, Findley SD: ZnT-3, a putative transporter of zinc into synaptic vesicles. Proc Natl Acad Sci USA 1996, 93:14934-14939.

2. Wenzel HJ, Cole TB, Born DE, Schwartzkroin PA, Palmiter RD: Ultrastructural localization of zinc transporter-3 (ZnT-3) to synaptic vesicle membranes within mossy fiber boutons in the hippocampus of mouse and monkey. Proc Natl Acad Sci USA 1997, 94:12676-1268I.

3. Cole TB, Wenzel HJ, Kafer KE, Schwartzkroin PA, Palmiter RD: Elimination of zinc from synaptic vesicles in the intact mouse brain by disruption of the $\mathrm{ZnT3}$ gene. Proc Natl Acad Sci USA 1999, 96:1716-1721.

4. Budde T, Minta A, White JA, Kay AR: Imaging free zinc in synaptic terminals in live hippocampal slices. Neuroscience 1997, 79:347-358

5. Datki ZL, Hunya A, Penke B: A novel and simple fluorescence method for the measurement of presynaptic vesicular zinc release in acute hippocampal slices with a fluorescence plate reader. Brain Res Bull 2007, 74:183-187.

6. Ruiz A, Walker MC, Fabian-Fine R, Kullmann DM: Endogenous zinc inhibits GABA(A) receptors in a hippocampal pathway. Neurophysiol 2004, 91:1091-1096.

7. Vogt K, Mellor J, Tong G, Nicoll R: The actions of synaptically released zinc at hippocampal mossy fiber synapses. Neuron 2000, 26:187-196. 
8. Molnar P, Nadler JV: Synaptically-released zinc inhibits $\mathbf{N}$ methyl-D-aspartate receptor activation at recurrent mossy fiber synapses. Brain Res 200I, 9 10:205-207.

9. Ueno S, Tsukamoto M, Hirano T, Kikuchi K, Yamada MK, Nishiyama N, Nagano T, Matsuki N, lkegaya Y: Mossy fiber Zn2+ spillover modulates heterosynaptic $\mathrm{N}$-methyl-D-aspartate receptor activity in hippocampal CA3 circuits. J Cell Biol 2002, 158:215-220.

10. Ha C, Ryu J, Park CB: Metal ions differentially influence the aggregation and deposition of Alzheimer's beta-amyloid on a solid template. Biochemistry 2007, 46:6II8-6I25.

II. Walsh DM, Klyubin I, Fadeeva JV, Cullen WK, Anwyl R, Wolfe MS, Rowan MJ, Selkoe DJ: Naturally secreted oligomers of amyloid beta protein potently inhibit hippocampal long-term potentiation in vivo. Nature 2002, 416:535-539.

12. Deshpande A, Kawai H, Metherate R, Glabe CG, Busciglio J: A role for synaptic zinc in activity-dependent Abeta oligomer formation and accumulation at excitatory synapses. J Neurosci 2009, 29:4004-4015.

13. Huang X, Atwood CS, Moir RD, Hartshorn MA, Vonsattel JP, Tanzi RE, Bush Al: Zinc-induced Alzheimer's Abeta I-40 aggregation is mediated by conformational factors. J Biol Chem 1997, 272:26464-26470

14. Lee JY, Friedman JE, Angel I, Kozak A, Koh JY: The lipophilic metal chelator DP-I09 reduces amyloid pathology in brains of human beta-amyloid precursor protein transgenic mice. Neurobiol Aging 2004, 25:|3|5-1321.

15. Lee JY, Cole TB, Palmiter RD, Suh SW, Koh JY: Contribution by synaptic zinc to the gender-disparate plaque formation in human Swedish mutant APP transgenic mice. Proc Natl Acad Sci USA 2002, 99:7705-77I0.

16. Friedlich AL, Lee JY, van Groen T, Cherny RA, Volitakis I, Cole TB, Palmiter RD, Koh JY, Bush AI: Neuronal zinc exchange with the blood vessel wall promotes cerebral amyloid angiopathy in an animal model of Alzheimer's disease. J Neurosci 2004, 24:3453-3459.

17. Gonzalez C, Martin T, Cacho J, Brenas MT, Arroyo T, Garcia-Berrocal B, Navajo JA, Gonzalez-Buitrago JM: Serum zinc, copper, insulin and lipids in Alzheimer's disease epsilon 4 apolipoprotein E allele carriers. Eur J Clin Invest 1999, 29:637-642.

18. Rulon LL, Robertson JD, Lovell MA, Deibel MA, Ehmann WD, Markesber WR: Serum zinc levels and Alzheimer's disease. Biol Trace Elem Res 2000, 75:79-85.

19. Deibel MA, Ehmann WD, Markesbery WR: Copper, iron, and zinc imbalances in severely degenerated brain regions in Alzheimer's disease: possible relation to oxidative stress. I Neurol Sci 1996, 143: 137-142.

20. Danscher G, Jensen KB, Frederickson CJ, Kemp K, Andreasen A, Juhl $S$, Stoltenberg M, Ravid R: Increased amount of zinc in the hippocampus and amygdala of Alzheimer's diseased brains: a proton-induced $\mathbf{X}$-ray emission spectroscopic analysis of cryostat sections from autopsy material. J Neurosci Methods 1997, 76:53-59.

21. Religa D, Strozyk D, Cherny RA, Volitakis I, Haroutunian V, Winblad B, Naslund J, Bush Al: Elevated cortical zinc in Alzheimer disease. Neurology 2006, 67:69-75.

22. Lovell MA, Robertson JD, Teesdale WJ, Campbell JL, Markesbery WR: Copper, iron and zinc in Alzheimer's disease senile plaques. J Neurol Sci 1998, I 58:47-52.

23. Suh SW, Jensen KB, Jensen MS, Silva DS, Kesslak PJ, Danscher G, Frederickson C): Histochemically-reactive zinc in amyloid plaques, angiopathy, and degenerating neurons of Alzheimer's diseased brains. Brain Res 2000, 852:274-278.

24. Miller LM, Wang Q, Telivala TP, Smith RJ, Lanzirotti A, Miklossy J: Synchrotron-based infrared and $X$-ray imaging shows focalized accumulation of $\mathrm{Cu}$ and $\mathrm{Zn}$ co-localized with beta-amyloid deposits in Alzheimer's disease. J Struct Biol 2006, I 55:30-37.

25. Regland B, Lehmann W, Abedini I, Blennow K, Jonsson M, Karlsson I, Sjogren M, Wallin A, Xilinas M, Gottfries CG: Treatment of Alzheimer's disease with clioquinol. Dement Geriatr Cogn Disord 200I, 1 2:408-414.

26. Ritchie CW, Bush Al, Mackinnon A, Macfarlane S, Mastwyk M, MacGregor L, Kiers L, Cherny RA, Li QX, Tammer A, Carrington D, Mavros C, Volitakis I, Xilinas M, Ames D, Davis S, Beyreuther K, Tanzi RE, Masters CL: Metal-protein attenuation with iodochlorhydrox- yquin (clioquinol) targeting Abeta amyloid deposition and toxicity in Alzheimer disease: a pilot phase 2 clinical trial. Arch Neurol 2003, 60: 1685-169|.

27. Zhang LH, Wang X, Zheng ZH, Ren H, Stoltenberg M, Danscher G, Huang $L$, Rong $M$, Wang $Z Y$ : Altered expression and distribution of zinc transporters in APP/PSI transgenic mouse brain. Neurobiol Aging 2008, 3 I(I):74-87.

28. Zhang LH, Wang X, Stoltenberg M, Danscher G, Huang L, Wang ZY: Abundant expression of zinc transporters in the amyloid plaques of Alzheimer's disease brain. Brain Res Bull 2008, 77:55-60.

29. Bustin SA: Quantification of mRNA using real-time reverse transcription PCR (RT-PCR): trends and problems. J Mol Endocrinol 2002, 29:23-39.

30. Ginzinger DG: Gene quantification using real-time quantitative PCR: an emerging technology hits the mainstream. Exp Hematol 2002, 30:503-512.

3I. Coulson DT, Brockbank S, Quinn JG, Murphy S, Ravid R, Irvine GB Johnston JA: Identification of valid reference genes for the normalization of RT qPCR gene expression data in human brain tissue. BMC Mol Biol 2008, 9:46.

32. Braak H, Braak E, Bohl J: Staging of Alzheimer-related cortical destruction. Eur Neurol 1993, 33:403-408.

33. Yasojima K, McGeer EG, McGeer PL: High stability of mRNAs postmortem and protocols for their assessment by RT-PCR. Brain Res Brain Res Protoc 200I, 8:2 I2-2I8.

34. Harrison PJ, Heath PR, Eastwood SL, Burnet PW, McDonald B, Pearson RC: The relative importance of premortem acidosis and postmortem interval for human brain gene expression studies: selective mRNA vulnerability and comparison with their encoded proteins. Neurosci Lett 1995, 200:151-154.

35. Preece $P$, Cairns NJ: Quantifying mRNA in postmortem human brain: influence of gender, age at death, postmortem interval, brain $\mathrm{pH}$, agonal state and inter-lobe mRNA variance. Brain Res Mol Brain Res 2003, I I 8:60-7I.

36. Li JZ, Vawter MP, Walsh DM, Tomita H, Evans SJ, Choudary PV, Lopez JF, Avelar A, Shokoohi V, Chung T, Mesarwi O, Jones EG, Watson SJ, Akil H, Bunney WE Jr, Myers RM: Systematic changes in gene expression in postmortem human brains associated with tissue $\mathrm{pH}$ and terminal medical conditions. Hum Mol Genet 2004, 13:609-616.

37. Livak KJ, Schmittgen TD: Analysis of relative gene expression data using real-time quantitative PCR and the 2(-Delta Delta C(T)) Method. Methods 200I, 25:402-408.

38. Hellemans J, Mortier G, De Paepe A, Speleman F, Vandesompele J: qBase relative quantification framework and software for management and automated analysis of real-time quantitative PCR data. Genome Biol 2007, 8:R I9.

39. McGeer PL, McGeer EG: The inflammatory response system of brain: implications for therapy of Alzheimer and other neurodegenerative diseases. Brain Res Brain Res Rev 1995, 21:195-218.

40. Simpson JE, Ince PG, Lace G, Forster G, Shaw PJ, Matthews F, Savva G, Brayne C, Wharton SB, on behalf of the MRC Cognitive Function and Ageing Neuropathology Study Group: Astrocyte phenotype in relation to Alzheimer-type pathology in the ageing brain. Neurobiol Aging 2008 in press.

4I. Smith JL, Xiong S, Markesbery WR, Lovell MA: Altered expression of zinc transporters- 4 and -6 in mild cognitive impairment, early and late Alzheimer's disease brain. Neuroscience 2006, 140:879-888.

42. Lee JY, Kim JH, Hong SH, Lee JY, Cherny RA, Bush Al, Palmiter RD, Koh JY: Estrogen decreases zinc transporter 3 expression and synaptic vesicle zinc levels in mouse brain. I Biol Chem 2004, 279:8602-8607.

43. Kantheti P, Qiao X, Diaz ME, Peden AA, Meyer GE, Carskadon SL, Kapfhamer D, Sufalko D, Robinson MS, Noebels JL, Burmeister M: Mutation in AP-3 delta in the mocha mouse links endosomal transport to storage deficiency in platelets, melanosomes, and synaptic vesicles. Neuron 1998, 2 I: I I I-I22.

44. Henderson VW: Estrogen-containing hormone therapy and Alzheimer's disease risk: understanding discrepant inferences from observational and experimental research. Neuroscience 2006, 138:1031-1039.

45. Jayasooriya AP, Ackland ML, Mathai ML, Sinclair AJ, Weisinger HS, Weisinger RS, Halver JE, Kitajka K, Puskas LG: Perinatal omega-3 
polyunsaturated fatty acid supply modifies brain zinc homeostasis during adulthood. Proc Natl Acad Sci USA 2005, 102:7|33-7|38.

46. Prasad MR, Lovell MA, Yatin M, Dhillon H, Markesbery WR: Regional membrane phospholipid alterations in Alzheimer's disease. Neurochem Res 1998, 23:81-88.

47. Saito T, Takahashi K, Nakagawa N, Hosokawa T, Kurasaki M, Yamanoshita O, Yamamoto Y, Sasaki H, Nagashima K, Fujita H: Deficiencies of hippocampal $\mathrm{Zn}$ and $\mathrm{ZnT3}$ accelerate brain aging of Rat. Biochem Biophys Res Commun 2000, 279:505-5I I.

Publish with Bio Med Central and every scientist can read your work free of charge

"BioMed Central will be the most significant development for disseminating the results of biomedical research in our lifetime. " Sir Paul Nurse, Cancer Research UK

Your research papers will be:

- available free of charge to the entire biomedical community

- peer reviewed and published immediately upon acceptance

- cited in PubMed and archived on PubMed Central

- yours - you keep the copyright

Submit your manuscript here:

http://www.biomedcentral.com/info/publishing_adv.asp
BioMedcentral 